\title{
Knowledge and awareness towards dengue infection and its prevention: a cross sectional study from rural area of Tamil Nadu, India
}

\author{
Vinoth Gnana Chellaiyan*, Aravind Manoharan, Murali Ramachandran
}

\begin{abstract}
Department of Community Medicine, Chettinad Hospital \& Research Institute, Kelambakkam, Chennai, Tamil Nadu,
\end{abstract} India

Received: 07 December 2016

Accepted: 02 January 2017

*Correspondence:

Dr. Vinoth Gnana Chellaiyan,

E-mail: drchellaiyan@gmail.com

Copyright: ( ) the author(s), publisher and licensee Medip Academy. This is an open-access article distributed under the terms of the Creative Commons Attribution Non-Commercial License, which permits unrestricted non-commercial use, distribution, and reproduction in any medium, provided the original work is properly cited.

\begin{abstract}
Background: Dengue infection transmitted by Aedes aegypti is endemic in India. Environmental changes and lack of awareness result in increase in transmission of dengue infection and rise in dengue outbreaks. The present study was conducted to determine the knowledge of dengue infection and practices towards dengue prevention among a rural population in Kancheepuram district of Tamil Nadu.

Methods: The study was cross sectional study, conducted in Kadambadi village of Kanchipuram district, Tamil Nadu. The study was conducted among 224 study participants from June - August 2016. Systematic random sampling was followed for selecting the houses. A pretested, semi structured questionnaire was used. Significance of difference in proportions (qualitative variables) was calculated using Chi square test. Significance of $\mathrm{p}$ value was taken as $\mathrm{p}<$ 0.05 .

Results: Among the study participants, 210 (93.7\%) heard about dengue infection. Fifty percent of participants responded correctly the symptoms of dengue infection. $89 \%$ responded correctly that dengue is transmitted by Aedes mosquito. Around $40 \%$ of the participants had correct knowledge about the breeding habitat and biting habit of Aedes mosquito. Study participants use various methods - mosquito coils $(63.4 \%)$, mosquito nets (14.7\%) for mosquito bite prevention. $24.1 \%$ does not follow any method of mosquito bite prevention.

Conclusions: Though majority of the study participants heard about dengue symptoms and mosquito transmitting dengue infection, less than half were aware about breeding habits of Aedes mosquito and $25 \%$ did not follow any method of mosquito bite prevention practices. Community awareness is a key role in improvising dengue prevention practices.
\end{abstract}

Keywords: Awareness, Dengue infection, Knowledge, Practices, Rural area

\section{INTRODUCTION}

Dengue a mosquito-borne viral disease has rapidly spread in all regions of $\mathrm{WHO}$ in recent years. ${ }^{1}$ The number of dengue cases reported annually to WHO has increased from 0.4 to 1.3 million in the decade 1996-2005, reaching 2.2 million in 2010 and 3.2 million in $2015 .^{2}$ In the last 50 years, incidence has increased 30-fold with increasing geographic expansion to new countries and in the present decade, from urban to rural settings. ${ }^{3}$ The estimated global annual incidence of symptomatic cases is about 50 million - 100 million who were predominantly from Asia, followed by Latin America and Africa. ${ }^{4}$

In India, 16517 cases and 545 deaths were reported during 1996 dengue outbreak after which there was upsurge of cases from 2010 onwards. In 2015, 99913 
cases have been reported which were higher than the cases reported in 2014. Tamil Nadu reported $4.5 \%$ of the national burden in the year 2015.5,6 Overall burden of disease is appearing sleek due to the substantial underreporting of dengue within health systems. ${ }^{7}$

The disease was mainly restricted to urban and semiurban areas of the country because of the availability of favorable breeding sites of dengue vector. However, over period of time there was a paradigm shift in the trend of incidence of dengue from urban to rural areas due to urbanization, industrialization, large scale development activities and rapid transportation which made the rural areas favorable for dengue vector breeding. These developments have resulted in frequent outbreaks of dengue in rural areas of the country. ${ }^{8}$ Rapid population growth, lack of correct knowledge about dengue infection and preventive measures, environmental changes and increased breeding of Aedes in the living premises resulted in higher transmission of disease. ${ }^{9,10}$

Considering the severity of the disease it has become need of the hour to adopt preventive and control measures to halt the transmission of dengue. This in turn depends on the community acceptance and participation which again depends on the community awareness regarding dengue and its prevention. With this background the study was conducted to determine the awareness about dengue and its prevention among a rural population in Kancheepuram district of Tamil Nadu state.

\section{METHODS}

Study setting: The study was a cross sectional study conducted in Kadambadi village which is in Kanchipuram district of Tamil Nadu State.

Study duration: The study was conducted from June August 2016 which is pre-monsoon period of south India.

Sample size determination: Assuming the prevalence of good awareness about dengue fever and its prevention as $50 \%$, along with absolute precision of $7 \%$ and a nonresponse rate of $10 \%$, the sample size arrived was 224 .

Sampling and study population: The study population comprised of residents of Kadambadi village of Thirukalukundram block of Kanchipuram district. According to census 2011, there were 13 blocks/ municipalities in Kanchipuram district. Among the 13 blocks, Thirukalukundram block was selected by simple random sampling. Out of 54 villages in Thirukalukundram block, Kadambadi village was selected by simple random sampling with lottery method. Kadambadi village had a total population of 1774 with 915 males and 859 females residing in 440 houses. Houses in the village were enumerated and study participants were enrolled by systematic random sampling method i.e. from alternate houses after choosing the first house randomly by lottery method numbered one to ten. This process was followed until the required sample was reached. One person from one house is included -either Male or female whosoever available at the house at the time of data collection. If in a house both male and female are available at the time of data collection, male and females were alternatively included in such cases.

The inclusion criteria were -1 ) Residents of age $\geq 18$ years, 2) Resident of the village for more than 6 months and 3) Willing to participate in the study. Those who cannot be contacted even after three visits were excluded.

Data collection procedure: The study participants were given subject information sheet and explained about the study and written informed consent was obtained. All the enrolled participants were interviewed in their door steps using pre-tested, semi-structured questionnaire by trained investigators in the local language i.e. Tamil.

Study tool: The study tool comprised of three sections. Section I comprised of Socio- demographic details such as age, sex, education, occupation, type of family and socioeconomic status (modified B G Prasad classification). Section II was about Community perception regarding mosquito borne disease and dengue in particular. This includes source of information about Mosquito borne disease, diseases transmitted by mosquito, previous exposure to dengue infection, cause of dengue and its transmission, vector bionomics and its life cycle, knowledge about symptoms of dengue and treatment for dengue fever. Section III was about awareness regarding prevention of Dengue i.e. subjective view on dengue prevention, preventive measures against mosquito breeding, personal protective measures against mosquito bite, Government measures and actions taken by Government to prevent dengue and the effective method to prevent and control dengue. The study instrument was pretested among 20 residents in Chrompet, an urban area of Chennai in June 2016 and necessary changes have been made.

Outcome variables: Outcome variables include those which assess the knowledge of dengue infectionsymptoms, mosquito transmitting and its breeding and biting habits and preference to seek care.

Statistical analysis: Data was entered in Microsoft Excel Spread Sheet. The study questionnaire was checked for completeness and correctness before entering into the worksheet. Data validation checks were performed at a regular interval for data entered into the worksheet of MS Excel. Data was analysed with Statistical Package for Social Sciences (SPSS IBM) version 21.0. The qualitative variables are described in the form of proportions and quantitative variables are described in the terms of mean, median, range and standard deviation. Data was checked for normality before applying appropriate tests of significance. Significance of difference in proportions (qualitative variables) was 
calculated using chi square test. Significance of $p$ value was taken as $\mathrm{p}<0.05$.

Ethical consideration and confidentiality: Institutional Ethical Committee approval was obtained before starting of the study. Confidentiality of study participants was maintained in all the phases of the study.

\section{RESULTS}

The study was conducted among 224 participants with a response rate of $100 \%$. The age of the participants ranged from 19 to 64 years with mean (SD) of $35( \pm 12.7)$. Among them $20.5 \%$ were illiterates and majority (67.4\%) belong to nuclear family. Among the females, 82 were homemakers (Table 1).

Table 1: Baseline characteristics of study participants. $(n=224)$.

\begin{tabular}{|ll|}
\hline Socio-demographic profile & $\mathbf{N}(\%)$ \\
Gender & $102(45.5)$ \\
Fale & $122(54.5)$ \\
\hline Age group & \\
$18-30$ & $89(39.7)$ \\
$31-45$ & $85(37.9)$ \\
$46-60$ & $38(17)$ \\
$>60$ & $12(5.4)$ \\
\hline Education & \\
Illiterate & $46(20.5)$ \\
Primary & $13(5.8)$ \\
Middle & $20(8.9)$ \\
Higher secondary & $99(44.2)$ \\
Graduate and above & $46(20.5)$ \\
\hline Occupation & \\
Professional & $8(3.6)$ \\
Clerk/Shop owners & $19(8.5)$ \\
Skilled & $17(7.6)$ \\
Semiskilled & $48(21.4)$ \\
Unskilled & $26(11.6)$ \\
Unemployed & $24(10.7)$ \\
Home maker & $82(36.6)$ \\
\hline Socio economic class* & \\
Class I & $158(70.5)$ \\
Class II & $66(29.5)$ \\
Class III & - \\
Class IV & - \\
\hline Type of family & $157(67.4)$ \\
Nuclear & $73(32.6)$ \\
Joint & \\
\hline Modified BG Prasad & \\
\hline
\end{tabular}

*Modified BG Prasad classification

Among the study participants, 210 (93.7\%) heard about dengue infection. The source of information was from Television $(67.8 \%)$, followed by health care providers (38.3\%) and newspaper (29\%). $80 \%$ of the study participants correctly responded the diseases transmitted by mosquito. $89 \%$ responded correctly that dengue is transmitted by Aedes mosquito. 4(1.2\%) had acquired dengue infection previously. $20 \%$ of study participants' friends, neighbours and relatives had dengue infection previously. Around $40 \%$ of the participants had correct knowledge about the breeding habitat and biting habit of Aedes mosquito. Around $56 \%$ of the study participants said that Aedes mosquito breeds in dirty stagnant water. Fifty percent of participants identified correctly the symptoms of dengue infection. Majority (75.9\%) of study participants prefer public health sector for seeking treatment for dengue infection (Table 2).

Table 2: Knowledge regarding mosquito borne diseases and health seeking behavior $(n=224)$.

\begin{tabular}{|c|c|}
\hline Knowledge and health seeking behaviour & $\mathbf{N}(\%)$ \\
\hline \multicolumn{2}{|l|}{ Heard about Dengue } \\
\hline Yes & $210(93.7)$ \\
\hline No & $14(6.3)$ \\
\hline \multicolumn{2}{|l|}{ Source of information* } \\
\hline Television & $152(67.8)$ \\
\hline Health care providers & $86(38.3)$ \\
\hline News paper & $65(29.0)$ \\
\hline Public displays & $61(27.2)$ \\
\hline Radio & $59(26.3)$ \\
\hline Others & $5(2.2)$ \\
\hline \multicolumn{2}{|l|}{ Name of the dengue transmitting } \\
\hline Incorrect response & $199(88.8)$ \\
\hline Correct response & $25(11.2)$ \\
\hline \multicolumn{2}{|l|}{ Dengue mosquito breeding habit* } \\
\hline Stagnant dirty water & $131(55.8)$ \\
\hline $\begin{array}{l}\text { Stagnant clean water (artificial collection of } \\
\text { water) }\end{array}$ & $87(38.8)$ \\
\hline Running clean water & $3(1.3)$ \\
\hline Plants \& Vegetation & $1(0.4)$ \\
\hline \multicolumn{2}{|l|}{ Dengue biting habits } \\
\hline Day & $87(38.8)$ \\
\hline Both Day and night & $80(35.7)$ \\
\hline Night & $39(17.4)$ \\
\hline \multicolumn{2}{|l|}{ Symptoms of Dengue } \\
\hline Correct response & $112(50.0)$ \\
\hline Incorrect response & $64(28.6)$ \\
\hline \multicolumn{2}{|l|}{ Knowledge on preventive measures* } \\
\hline Keeping surroundings clean & $195(87.0)$ \\
\hline $\begin{array}{l}\text { Removal of artificial collection of water } \\
\text { from premises }\end{array}$ & $85(37.9)$ \\
\hline Proper drainage & $105(46.9)$ \\
\hline Spraying chemicals on water & $17(7.6)$ \\
\hline Don't know & $3(1.3)$ \\
\hline \multicolumn{2}{|l|}{ Exposure to dengue infection before } \\
\hline No & $220(98.2)$ \\
\hline Yes & $4(1.8)$ \\
\hline \multicolumn{2}{|l|}{$\begin{array}{l}\text { Preference to seek treatment for dengue } \\
\text { infection* }\end{array}$} \\
\hline Public health sector & $170(75.9)$ \\
\hline Private Clinics/ hospitals & $75(33.5)$ \\
\hline Home remedy & $5(2.2)$ \\
\hline Traditional Healers & $3(1.3)$ \\
\hline No treatment is required & $5(2.2)$ \\
\hline
\end{tabular}

*Multiple response 
Majority of study participants $(63.4 \%)$ use mosquito coils for prevention of mosquito bites at their home. Only $14.7 \%$ use mosquito bed nets and $24.1 \%$ does not follow any method of mosquito bite prevention. Only $11.2 \%$ use insecticide treated bed nets. According to the participants most effective measure in preventing the mosquito breeding and biting is chemical measures which includes space sprays, mosquito repellants, coils, and repellant liquids (Table 3).

The proportion of participants who had higher education are better aware about the breeding and biting habits of Aedes mosquito when compared to those who are illiterates and had primary school education. This was found to be statistically significant. $(\mathrm{p}=0.000)$. Those who belong to nuclear family had better knowledge on Aedes breeding and biting habits. $(\mathrm{p}=0.043)$ Also, participants who are from joint family are aware about at least one method of prevention when compared to participants from nuclear family $(\mathrm{p}=0.01)$ (Table 4$)$.

Table 3: Practice of prevention of Dengue $(n=224)$.

\begin{tabular}{|ll|}
\hline Practice of dengue prevention & N $(\%)$ \\
\hline Using personal protective measures* & \\
Mosquito coils & $142(63.4)$ \\
Bed nets & $33(14.7)$ \\
Insecticide treated bed nets & $25(11.2)$ \\
Repellant cream & $23(10.3)$ \\
Repellant Spray & $8(3.6)$ \\
Nothing & $54(24.1)$ \\
\hline Most effective measure & \\
Chemical & $118(52.7)$ \\
Environmental & $65(29.0)$ \\
Biological & $18(8.0)$ \\
Integrated & $9(4.0)$ \\
Don't know & $14(6.2)$ \\
\hline
\end{tabular}

Table 4: Association of knowledge about dengue infection and prevention measures with selected variables (n=224).

\begin{tabular}{|c|c|c|c|c|c|c|}
\hline \multirow[t]{2}{*}{ Variables } & \multicolumn{3}{|c|}{$\begin{array}{l}\text { Aware about Aedes mosquito breeding } \\
\text { and biting habit }\end{array}$} & \multicolumn{3}{|c|}{$\begin{array}{l}\text { Aware about at least one preventive } \\
\text { method }\end{array}$} \\
\hline & Yes $(\mathrm{N}=87)$ & No $(N=137)$ & $p$ value & Yes $(\mathrm{N}=148)$ & No $(N=76)$ & $p$ value \\
\hline $\begin{array}{l}\text { Gender } \\
\text { Male } \\
\text { Female }\end{array}$ & $\begin{array}{l}36(35.3) \\
51(41.8)\end{array}$ & $\begin{array}{l}66(64.7) \\
71(58.2)\end{array}$ & 0.320 & $\begin{array}{l}67(65.7) \\
81(66.4)\end{array}$ & $\begin{array}{l}35(34.3) \\
41(33.6)\end{array}$ & 0.911 \\
\hline $\begin{array}{l}\text { Age group } \\
18-30 \\
31-45 \\
46-60 \\
>60\end{array}$ & $\begin{array}{l}41(46.1) \\
32(37.6) \\
12(31.6) \\
2(16.7)\end{array}$ & $\begin{array}{l}48(53.9) \\
53(62.4) \\
26(68.4) \\
10(83.3)\end{array}$ & 0.149 & $\begin{array}{l}55(61.8) \\
63(74.1) \\
25(65.8) \\
5(41.7)\end{array}$ & $\begin{array}{l}34(38.2) \\
22(25.9) \\
13(34.2) \\
7(58.3)\end{array}$ & 0.095 \\
\hline $\begin{array}{l}\text { Education } \\
\text { Illiterate } \\
\text { Primary } \\
\text { Middle } \\
\text { Higher secondary } \\
\text { Graduate \& above }\end{array}$ & $\begin{array}{l}6(13) \\
3(23.1) \\
5(25.0) \\
39(29.4) \\
34(73.9)\end{array}$ & $\begin{array}{l}40(87) \\
10(76.9) \\
15(75.0) \\
60(60.6) \\
12(26.1)\end{array}$ & 0.000 & $\begin{array}{l}29(63) \\
7(53.8) \\
10(50.0) \\
68(68.7) \\
34(73.9)\end{array}$ & $\begin{array}{l}17(37) \\
6(46.2) \\
10(50.0) \\
31(31.3) \\
12(26.1)\end{array}$ & 0.295 \\
\hline $\begin{array}{l}\text { Occupation } \\
\text { Professional } \\
\text { Clerk/Shopowners } \\
\text { Skilled } \\
\text { Semiskilled } \\
\text { Unskilled } \\
\text { Unemployed } \\
\text { Home maker }\end{array}$ & $\begin{array}{l}7(87.5) \\
4(21.1) \\
10(58.8) \\
20(41.7) \\
6(23.1) \\
11(45.8) \\
29(35.4)\end{array}$ & $\begin{array}{l}1(12.5) \\
15(78.9) \\
7(41.2) \\
28(58.3) \\
20(76.9) \\
13(54.2) \\
53(64.6)\end{array}$ & 0.09 & $\begin{array}{l}6(75.0) \\
15(78.9) \\
11(64.7) \\
38(79.2) \\
14(53.8) \\
10(41.7) \\
54(65.9)\end{array}$ & $\begin{array}{l}2(25.0) \\
4(21.1) \\
6(35.3) \\
10(20.8) \\
12(46.2) \\
14(58.3) \\
28(34.1)\end{array}$ & 0.036 \\
\hline $\begin{array}{l}\text { SE class* } \\
\text { Class I } \\
\text { Class II }\end{array}$ & $\begin{array}{l}36(35.3) \\
51(41.8)\end{array}$ & $\begin{array}{l}66(64.7) \\
71(58.2)\end{array}$ & 0.320 & $\begin{array}{l}107(67.7) \\
40(60.6)\end{array}$ & $\begin{array}{l}51(32.3) \\
26(39.4)\end{array}$ & 0.522 \\
\hline $\begin{array}{l}\text { Type of family } \\
\text { Nuclear } \\
\text { Joint }\end{array}$ & $\begin{array}{l}65(43.0) \\
22(30.0)\end{array}$ & $\begin{array}{l}86(57.0) \\
51(69.9)\end{array}$ & 0.043 & $\begin{array}{l}89(58.9) \\
59(80.8)\end{array}$ & $\begin{array}{l}62(41.1) \\
14(19.2)\end{array}$ & 0.01 \\
\hline
\end{tabular}

*SE- socio-economic, Chi square test applied, $\mathrm{p}$ value $<0.05$ is significant.

\section{DISCUSSION}

The present study explored the knowledge and preventive practices regarding Dengue infection among the rural community of Tamil Nadu as it is one of the state hit by dengue outbreaks during post monsoon periods. It was found in the present study that knowledge about biting and breeding habits was much higher in those who had 
higher education. This finding is consistent with other studies done by Kohli $\mathrm{C}$ et al and Sharma AK et al. ${ }^{11,12}$ Knowledge about breeding habits and preventive measures did not significantly differ by gender. This is similar to previous studies done by Van Benthem BH et al and Kohli et al where knowledge did not have a significant difference. ${ }^{11,13}$

In the present study, $93.7 \%$ had heard about dengue infection. In a study done in a rural community by Malhotra $\mathrm{G}$ et al around $60 \%$ of the respondents had previously heard about dengue fever. ${ }^{14}$ In another study done in urban settlement area of South Delhi, 90\% reported of being aware of dengue, $78 \%$ in a study done in Brazil whereas in Thailand knowledge about dengue was $67 \% .{ }^{15-17}$ Though the present study was done in rural area, the knowledge about dengue was at par with urban area due to better awareness about the disease.

In the present study, $89 \%$ said correctly that dengue is transmitted by Aedes mosquito. Malhotra $G$ et al reported that $72.62 \%$ respondents mentioned mosquito bite as cause of dengue similar to study done in Brazil. ${ }^{14,16}$ Swaddiwudhipong et al reported that $>90 \%$ respondents knew the disease is transmitted by Aedes mosquitoes. ${ }^{17}$

In our study, Fifty percent of participants identified correctly the symptoms of dengue infection. The study done by Gupta et al reported $92 \%$ knew about fever followed by headache as a symptom of dengue whereas in Degallier $\mathrm{N}$ et al and Benthem et al studies, majority identified the symptoms rash or bleeding specific for dengue infection to distinguish dengue infection from other diseases. ${ }^{13,16,18}$ Correct knowledge on symptoms of dengue is very essential and helps in early reporting to health care system.

In the present study, around $40 \%$ of the participants had correct knowledge about the breeding habitat and biting habit of Aedes mosquito. However in a study done by Matta et al found that, $79.8 \%$ respondents knew about breeding places of mosquitoes. There is a substantial gap in the correct knowledge about the breeding and biting habits of Aedes mosquito in our study. ${ }^{19}$ This issue needs to addressed with targeted information dissemination and to educate the community on preventive measures to combat dengue.

Majority of study participants (63.4\%) use mosquito coils, bed nets $(14.7 \%)$ insecticide treated bed nets $(11.2 \%)$ and other measures for prevention of mosquito mosquito bites at their home. In previous study by Malhotra $\mathrm{G}$ et al found that most respondents were aware of measures like window screening, mosquito mat/coil/liquid vaporizer/ repellent cream, use of bed nets, using fans, use of smoke to drive away the mosquitoes especially both rural and slum areas. ${ }^{14}$ Itrat A et al and Hairi F et al had reported these methods to be most effective means of preventions..$^{20,21}$

\section{CONCLUSION}

From our study findings, it was clear that though majority of the study participants heard about dengue symptoms and mosquito transmitting dengue infection, less than half were aware about breeding habits of Aedes mosquito and $25 \%$ did not follow any method of mosquito bite prevention practices. Hence it is recommended that health campaigns and health education should be more aggressive and targeted on preventive practices in future. Health education would be provided via various strategies including mass media and using audio visual aids in health campaigns. Also, these programs should also ensure putting into practice the knowledge acquired.

Funding: No funding sources

Conflict of interest: None declared

Ethical approval: The study was approved by the Institutional Ethics Committee

\section{REFERENCES}

1. Dengue and severe dengue (Fact sheet). World Health Organization, Geneva, Switzerland, 2016 [cited 18 August 2016].

2. Global Strategy for dengue prevention and control, 2012-2020. World Health Orga $\neg$ nization, Geneva, Switzerland, 2012.

3. World Health Organization. Dengue, guidelines for diagnosis, treatment, prevention and control. Geneva: World Health Organization; 2009. [Online] Available from: http://www.who.int/ tdr/publications/ documents/dengue-diagnosis.pdf [Accessed on 18 August 2016].

4. World Health Organization. Weekly epidemiological record. Dengue vaccine: WHO position paper - July 2016.

5. NCDC newsletter. Quarterly newsletter from National Centre for Disease Control. Volume 4 Issue 3. July-Sept 2015. Pg 21.

6. National Vector Borne Disease Control Program. Dengue [Internet]. Delhi. National Vector Borne Disease Control Program; July 2016. [cited July 2016]. Available from: http://www.nvbdcp.gov.in/den-cd.html.

7. Beatty ME, Beutels P, Meltzer MI, Shepard DS, Hombach J, Hutubessy R, Dessis D, et al. Health economics of dengue: a systematic literature review and expert panel's assessment. Am J Trop Med Hyg. 2011;84(3):473-88.

8. Jagtap MB, Sale LS, Bhosale AS, Sathe A, Sathe $\mathrm{TV}$. Incidence of dengue and shifting trend to rural in Kolhapur District, India. Biological Forum - An Int J. 2009;1(2):58-61.

9. Gubler DJ, Clark GG. Dengue/dengue hemorrhagic fever the emergence for a global health problem. Emerg Infect Dis. 1995:1:5557.

10. World Health Organization. Dengue hemorrhagic fever: Diagnosis, Treatment, Prevention and 
Control. 2nd ed. Geneva: World Health Organization; 1997.

11. Kohli C, Kumar R, Meena GS, Singh MM, Ingle G K.A Study on Knowledge and Preventive Practices about Mosquito Borne Diseases in Delhi. J MAMC Med Sci. 2015;1(1):16-9.

12. Sharma AK, Bhasin S, Chaturvedi S. Predictors of knowledge about malaria in India. J Vector Borne Dis. 2007;44:189-97.

13. Van Benthem BH, Khantikul N, Panart K, Kessels PJ, Somboon P, Oskam L. Knowledge and use of prevention measures related to dengue in northern Thailand. Trop Med Int Health. 2002;7:993-1000.

14. Malhotra G, Yadav A, Dudeja P. Knowledge, awareness and practices regarding dengue among rural and slum communities in North Indian city, India. Int J Med Sci Public Health. 2014;3:295-9.

15. Acharya A, Goswami K, Srinath S, Goswami A. Awareness about dengue syndrome and related preventive practices amongst residents of an urban resettlement colony of south Delhi. J Vect Borne Dis. 2005;42:122-7.

16. Dégallier N, Vilarinhos PT, de Carvalho MS, Knox MB, Caetano J Jr. People's knowledge and practice about dengue, its vectors, and control means in Brasilia (DF), Brazil: Its relevance with entomological factors. J Am Mosq Contr Assoc. 2000;16:114-23.

17. Swaddiwudhipong $\mathrm{W}$, Lerdlukanavonge $\mathrm{P}$, Khumklam P, Koonchote S, Nguntra P, Chaovakiratipong C. A survey of knowledge, attitude and practice of the prevention of dengue hemorrhagic fever in an urban community of Thailand. Southeast Asian J Trop Med Pub Health. 1992;23:207-11.

18. Gupta P, Kumar P, Aggarwal O. Knowledge, attitude and practices related to dengue in rural and slum areas of Delhi after the dengue epidemic of 1996. J Communicable Diseases. 1998;30(2):10712.

19. Matta S, Bhalla S, Singh D, Rasania SK, Singh S. Knowledge, Attitude and Practice (KAP) on Dengue fever: A Hospital Based Study. Indian J Community Med. 2006;31(3):185-6.

20. Itrat A, Khan A, Javaid S, Kamal M, Khan H, Javed $\mathrm{S}$, et al. Knowledge, awareness and practices regarding dengue fever among the adult population of dengue hit cosmopolitan. PLoS One. 2008;9(3):e2620.

21. Hairi F, Ong CH, Suhaimi A, Tsung TW, bin Anis Ahmad MA, Sundaraj C, et al. A Knowledge, attitude and practices (KAP) study on dengue among selected rural communities in the Kuala Kangsar district. Asia Pac J Public Health. 2003;15(1):37-43.

Cite this article as: Chellaiyan VG, Manoharan A, Ramachandran M. Knowledge and awareness towards dengue infection and its prevention: a cross sectional study from rural area of Tamil Nadu, India. Int J Community Med Public Health 2017;4:494-9. 